\title{
HOW TO CHOOSE THE THIRD PARAMETER IN WILSON'S EQUATION
}

MitsuYASU HIRANUMA

Tomakomai Technical College, Tomakomai, 059-12

\section{Introduction}

In 1964, Wilson ${ }^{13)}$ proposed an equation for $g^{E}$, the molar excess Gibbs energy of a liquid mixture; for a binary, it can be written in the following form:

$$
\begin{aligned}
& g^{E} / R T=-c\left\{x_{1} \ln \left(x_{1}+\Lambda_{12} x_{2}\right)+x_{2} \ln \left(x_{2}+\Lambda_{21} x_{1}\right)\right\} \\
& \Lambda_{i j}=\left(v_{j} / v_{i}\right) \exp \left\{-\left(\lambda_{i j}-\lambda_{i i}\right) / R T\right\}
\end{aligned}
$$

where $\lambda_{i j}$ is an energy parameter characterizing the interaction between molecules $i$ and $j$.

As pointed out by Wilson, Eq. (1) with $c \neq 1$ is applicable to liquid mixtures which are only partially miscible $^{12)}$. Renon and Prausnitz ${ }^{11)}$ found that $c=$ $z / 2$, where $z$ is the coordination number of the liquid, and Cuckor and Prausnitz ${ }^{5)}$ studied its utility.

For typical liquids, the coordination number is in the range $6 \sim 12$. However, the three-parameter Wilson equation with $z=6 \sim 12$ does not give a good fit for a partially miscible mixture or for a mixture of an alcohol with a nonpolar substance.

In this paper, the physical meaning of the value $z$ and how to choose it, particularly for a very nonideal system, are discussed.

\section{How to Choose the Value of $z$}

The effect of the value of $z$ was studied on the accuracy of the correlation of vapor-liquid equilibria.

A nonlinear least-square fitting method was used which minimizes the sum of squares of deviations in activity coefficients for all vapor-liquid data points.

Results of 16 systems are presented in Table $\mathbf{1}$.

Partially miscible mixtures provide the best test for the value of $z$, because liquid-liquid equilibrium data are much more sensitive to the value of $z$.

Data for four ternary partially miscible systems were chosen $^{7)}$ and representative results of two systems are presented in Figs. 1 and $\mathbf{2}$.

For a multicomponent system, the value of $z$ chosen for the most nonideal binary was used for all constituent binaries.

When liquids are classified into four groups by the strength of bonds (Class A: hydrogen bonded liquids $\left(\mathrm{A}_{1}=\mathrm{a}\right.$ linear bonded molecule, $\mathrm{A}_{2}=$ water $)$; Class EP: a molecule with an 'exposed' or localized polar part,

\footnotetext{
Received June 22, 1974.
}

such as nitromethane and acetonitrile; Class P: polar liquids; Class N: nonpolar liquids), the value of $z$ is estimated according to the combination of these groups. These are:

(1) For the system $(P+N$ and $N+N)$, the effect due to $z>2$ is small in most cases, as shown in Table 1 (A), though values of $z$ more than 2 must be suitable for such a system.

(2) For the system $\left(A_{1}+N\right.$ and $\left.E P+N\right)$, it is necessary that $z \simeq 2$, as shown in Table 1 (B).

(3) For the system $(\mathrm{P}+\mathrm{P})$, the effect of $z$ is not found in Table $1(\mathrm{C})$, though $z \rightarrow 2$ is expected with the strength of solvation.

(4) For an aqueous solution $\left(\mathrm{A}_{2}+\mathrm{P}\right.$ and $\left.\mathrm{A}_{2}+\mathrm{A}_{1}\right)$, $z=3 \sim 2$ with the strength of solvation, as shown in Table 1 (D).

As another example, for the system acetone-methyl acetate $(\mathrm{P})$-water $\left(\mathrm{A}_{2}\right), z=2.4$ was suitable.

(5) For an aqueous system whose components are essentially immiscible $\left(\mathrm{A}_{2}+\mathrm{N}\right.$ or $\left.\mathrm{P}\right)$, it is necessary that $z \simeq 3$ (Fig. 1). As another example, for the

Table 1 Effect of the value of $z$ on the accuracy of

\begin{tabular}{|c|c|c|c|c|}
\hline System & $\begin{array}{l}\text { Temp. } \\
{\left[{ }^{\circ} \mathrm{C}\right]}\end{array}$ & \multicolumn{2}{|c|}{$\sigma_{y}$} & Lit. \\
\hline (A) & & $z=2$ & $z=4$ & \\
\hline Acetone-Cyclohexane & 55 & 8.21 & 6.29 & (4) \\
\hline Acetone- $\mathrm{CCl}_{4}$ & 45 & 5.17 & 5.76 & (3) \\
\hline Acetone-Hexane & 55 & 11.67 & 10.48 & (4) \\
\hline Benzene-Heptane & 45 & 5.93 & 6.35 & (10) \\
\hline $\begin{array}{l}\text { Carbon disulfide- } \\
\text { Acetone }\end{array}$ & 35.17 & 4.20 & 4.35 & (8) \\
\hline (B) & & & & \\
\hline Acetonitrile-Benzene & 45 & 11.24 & 12.78 & (10) \\
\hline $\mathrm{CCl}_{4}$-Acetonitrile & 45 & 4.58 & 16.18 & (2) \\
\hline Cyclohexane-Ethanol & 25 & 10.19 & 16.30 & (8) \\
\hline Ethanol-Benzene & 50 & 4.34 & 12.02 & (1) \\
\hline Nitromethane- $\mathrm{CCl}_{4}$ & 45 & 4.55 & 11.66 & (9) \\
\hline (C) & & & & \\
\hline Acetone-Methyl acetate & 30 & 6.73 & 6.73 & (4) \\
\hline Acetone-Chloroform & 35.17 & 3.42 & 3.42 & (8) \\
\hline (D) & & $z=2$ & $z=3$ & \\
\hline Acetone-Water & 25 & 11.55 & 11.37 & (8) \\
\hline Dioxane-Water & 35 & 10.41 & 9.79 & (4) \\
\hline Ethanol-Water & 39.76 & 24.8 & 22.64 & (8) \\
\hline Water-Pyridine & 80.05 & 21.85 & 28.49 & (8) \\
\hline
\end{tabular}

representation of binary vapor-liquid data 


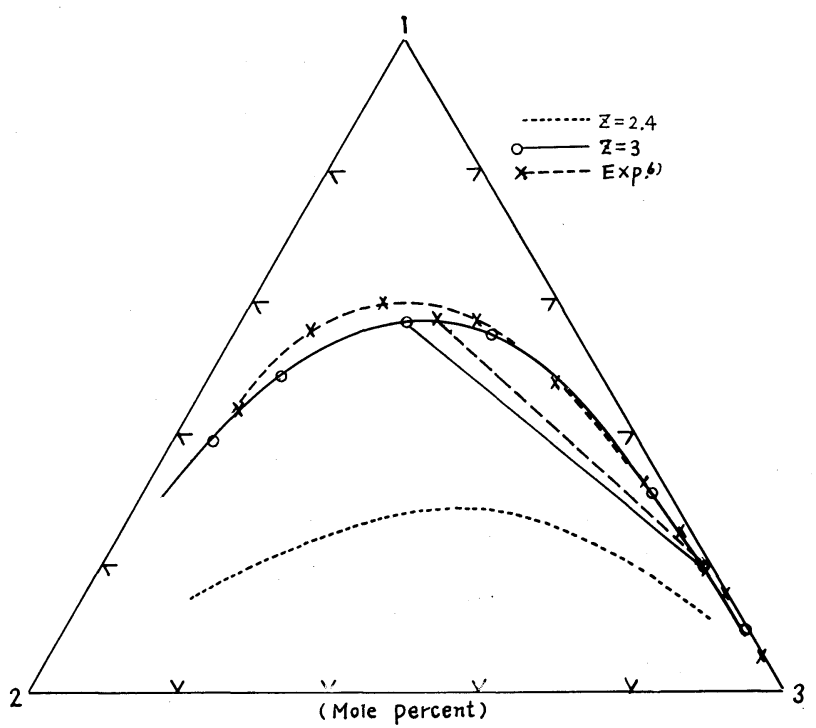

Fig. 1 Calculated and observed liquid-liquid equilibria for the system acetone(1)-chloroform(2)-water(3) at $25^{\circ} \mathrm{C}$ (Source of binary data: Lit. (8))

system ethanol-benzene $(\mathrm{N})$-water $\left(\mathrm{A}_{2}\right), z \simeq 3$ was suitable.

(6) For the system benzene-acetonitrile (EP)- $n$ heptane $(\mathrm{N}), z=2.2$ is very suitable, as shown in Fig. 2.

\section{Conclusion}

The value of $z$ is determined primarily by the hydrogen bonds for the systems in which association and/or solvation occur; dispersion forces have rather little effect on it.

\section{Literature Cited}

1) Brown, I. and F. Smith: Aust. J. Chem., 7, 264 (1954).

2) Brown, I. and F. Smith: ibid., 7, 269 (1954).

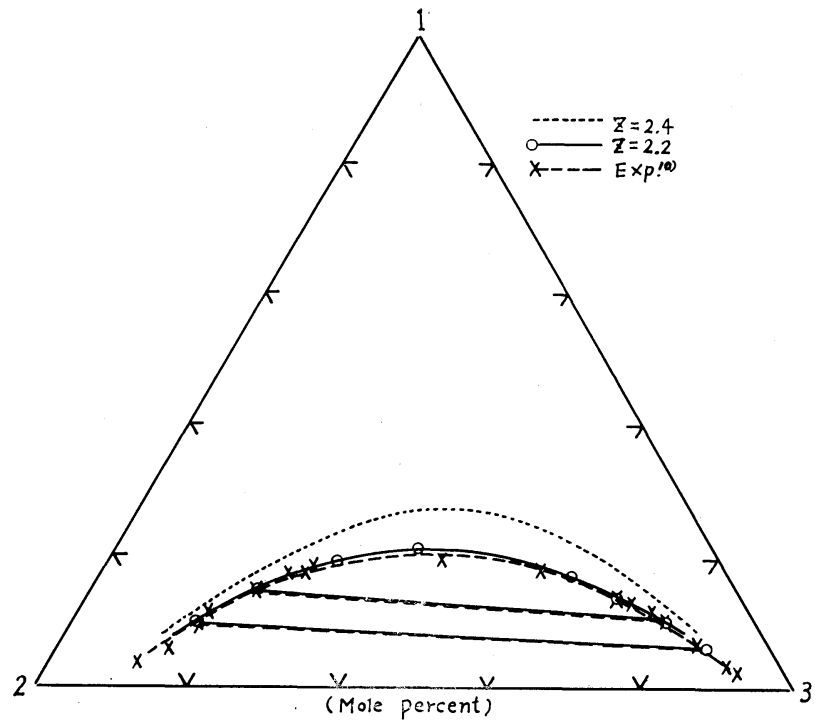

Fig. 2 Calculated and observed liquid-liquid equilibria for the system benzene(1)-heptane(2)-acetonitrile(3) at $45^{\circ} \mathrm{C}$ (Source of binary data: Lit. (10))

3) Brown, I. and F. Smith: ibid., 10, 423 (1957).

4) "Bussei Jyosu," vols. 1-8, Maruzen (1963-70).

5) Cuckor, P. M. and J. M. Prausnitz: I. Chem. E. Symposium Series No. 32, p. 88 (1969).

6) Hand, D. B.: J. Phys. Chem., 34, 1980 (1930).

7) Hiranuma, M.: Ind. Eng. Chem., Fundam., 13, 219 (1974).

8) "Kagaku Benran", Maruzen (1966).

9) Orye, R. V. and J. M. Prausnitz: Ind. Eng. Chem., 57, 18 (1965).

10) Palmer, D. A. and B. D. Smith: J. Chem. Eng. Data, 17, 73 (1972).

11) Renon, H. and J. M. Prausnitz: AIChE J., 15, 785 (1969).

12) Scatchard, G. and G. M. Wilson: J. Am. Chem. Soc., 86, 133 (1964).

13) Wilson, G. M.: ibid., 86, 127 (1964).

\section{LIMITING SHERWOOD NUMBER IN MULTIPARTICLE SYSTEM WITH STAGNANT FLUID}

Recently Wakao ${ }^{4)}$ showed that the numerically calculated Nusselt number of his definition becomes about 2 regardless of $k_{s} / k_{f}$, while Miyauchi ${ }^{2)}$ modified the results obtained from the free surface model proposed by Pfeffer and Happel ${ }^{3}$, showing that the limiting Sherwood number is greater than 10 for packed beds.

Obviously, Sherwood (or Nusselt) number varies

Received June 7, 1974. with the definition of mass transfer coefficient as was pointed out by Miyauchi for packed beds, as well as with the boundary conditions adopted in the course of determining mass flux at the surface of particles. In packed beds, the basic equations of mass transfer around a particle with stagnant fluid are given by the concentric sphere model as

$$
D\left(\frac{\partial^{2} c}{\partial r^{2}}+\frac{2}{r} \frac{\partial c}{\partial r}\right)=\frac{\partial c}{\partial t}
$$

